\title{
Association of insulin-like growth factor-1 with thyroid nodules
}

\author{
YING-JIAN LIU, WEI QIANG, XING-JUN LIU, LI XU, HUI GUO, LI-PING WU and BINGYIN SHI \\ Department of Endocrinology, The First Affiliated Hospital of Xi'an Jiaotong University School of Medicine, \\ Xi'an, Shaanxi 710061, P.R. China
}

Received March 4, 2011; Accepted August 12, 2011

DOI: $10.3892 / \mathrm{ol} .2011 .411$

\begin{abstract}
The aim of the present study was to investigate the relationship between insulin-like growth factor-1 (IGF-1) and thyroid nodules. A total of 56 patients with thyroid nodules confirmed by physical examination and ultrasound screening were randomly selected. The patients were divided into three groups by radionuclide scan: the hot nodule group (group 1, $\mathrm{n}=18$ ); the cold and solid nodule group (group 2, $\mathrm{n}=18$ ); and the cold and cystic nodule group (group 3, $n=20$ ). Cystic fluid samples from patients with cystic cold thyroid nodules were defined as group 4. A control group of 18 healthy adults matched for age, gender and body mass index (group 0) was also included. For all participants, levels of the thyroid hormones, TT3, TT4, TSH and IGF-1, were determined by radioimmunoassay. The measurement data were expressed as the mean \pm standard deviation (SD). The analysis of variance was performed by the t-test and the correlation analysis was performed by linear regression. The serum levels of IGF-1 in the solid cold nodule group were significantly higher than those in the hot nodule group $(\mathrm{P}<0.05)$. Serum levels of IGF-1 in the cystic cold nodule group were significantly lower than those in the control group $(\mathrm{P}<0.05)$. The serum IGF-1 levels in the cystic fluid were significantly lower than those in the cystic cold nodule $(\mathrm{P}<0.05)$ and the control groups $(\mathrm{P}<0.05)$. Additionally, the mean serum IGF-1 level in patients with thyroid adenoma was significantly higher than that in the control group $(\mathrm{P}<0.05)$. The serum IGF-1 level may not be involved in the pathogenesis of hot thyroid nodules and cold and cystic thyroid nodules; however, it may play a significant role in the pathogenesis of certain solid cold thyroid nodules.
\end{abstract}

\section{Introduction}

The thyroid gland is an endocrine organ situated at the front and sides of the neck, anterior to the trachea, just inferior to the larynx, and behind the sternohyoid and thyrohyoid muscles.

Correspondence to: Professor Bingyin Shi, Department of Endocrinology, The First Affiliated Hospital of Xi'an Jiaotong University School of Medicine, 277 Yanta West Road, Xi'an, Shaanxi 710061, P.R China

E-mail: shibingy@126.com

Key words: thyroid nodule, IGF-1, pathogenesis
Weighing approximately $20 \mathrm{~g}(15-25 \mathrm{~g})$ and measuring $2 \times 3 \mathrm{~cm}$ in adult humans, it consists of two lobes connected by an isthmus. It is a highly vascular organ, deriving its blood from the superior and inferior thyroid arteries. Microscopically, it is made up of spherical vesicles separated by connective tissue (1). The thyroid produces hormones that regulate the metabolism and are essential to the proper development and differentiation of the cells in the body. The use of imaging technology in the investigation of disorders of the head and neck has increased awareness of nodular thyroid disease in all areas of medicine. During inspection, nodules may manifest themselves as a swelling at localizations corresponding to the thyroid gland, whereas other nodules are found during palpation (2). Thyroid nodules are a common endocrine problem in the clinic, and present as various conditions, including thyroid cysts, thyroid adenomas and thyroid cancers (3). A nodule is a lump consisting of an abnormal growth of thyroid tissue within an otherwise normal thyroid gland, ranging in size from a few millimeters to a few centimeters. Nodules are believed to be a result of excessive distention of certain follicles that have undergone involution and of an increase in the regions of epithelial hyperplasia (2). Tumors derived from thyroid epithelial cells are among the most common clinically recognized neoplasms. The neoplasms include benign follicular adenomas, well-differentiated papillary or follicular carcinomas, poorly differentiated 'insular' carcinomas, and dedifferentiated or anaplastic carcinomas (4). However, the potential causes for thyroid nodules remain unidentified at present.

Insulin-like growth factor-1 (IGF-1, known as somatomedin C) is a small peptide hormone (molecular weight $7.647 \mathrm{kDa}$ ) (5). Circulating IGF-1 is bound to a family of insulin-like growth factor-binding proteins (IGFBPs). Most IGF-1 is carried by IGFBP-3 (6). In contrast to the pulsatile secretion of the growth hormone $(\mathrm{GH})$, serum IGF-1 levels are relatively stable, with modest diurnal variation (7). Measurements of the serum levels of IGF-1 have become essential laboratory tools in the management of somatotropic axis disorders in adolescents and adults. Previous studies investigated the potential role of IGF-1 in various diseases, including cardiovascular disease (8), cancer (9) and osteoporosis (10). Increases in systemically circulating IGF-1 levels were associated with an increased risk of numerous cancer types and more rapid disease progression (11). Epidemiological studies indicated that high circulating levels of IGF-1 were associated with an increased risk of second primary tumors (SPTs) of the head and neck (12), breast (13), 
Table I. Age, gender and body mass index distribution in each group (mean $\pm \mathrm{SD})$.

\begin{tabular}{lcccc}
\hline Group & No. & $\begin{array}{c}\text { Age } \\
\text { (years) }\end{array}$ & $\begin{array}{c}\text { Gender } \\
(\text { male/female })\end{array}$ & $\begin{array}{c}\text { BMI } \\
\left(\mathrm{kg} / \mathrm{m}^{2}\right)\end{array}$ \\
\hline 0 & 18 & $43.33 \pm 12.96$ & $6 / 12$ & $21.2 \pm 3.6$ \\
1 & 18 & $42.17 \pm 12.24$ & $5 / 13$ & $22.5 \pm 2.2$ \\
2 & 18 & $42.67 \pm 15.28$ & $6 / 12$ & $21.8 \pm 3.3$ \\
3 & 20 & $49.60 \pm 11.81$ & $8 / 14$ & $22.6 \pm 2.7$ \\
4 & 17 & $49.65 \pm 12.30$ & $6 / 11$ & $22.3 \pm 3.5$ \\
\hline
\end{tabular}

Group 0, control group; group 1, patients with hot thyroid nodules; group 2, patients with solid cold thyroid nodules; group 3, patients with cystic cold thyroid nodules; group 4, cystic fluid samples from patients with cystic cold thyroid nodules; BMI, body mass index.

prostate (14) and lung (15). Experimental evidence suggested that IGF-1 plays a significant role in the growth of thyroid cells, and is possibly involved in the pathogenesis of thyroidrelated diseases. One study found that IGF-1 stimulated protein and DNA synthesis and promoted the proliferation and differentiation of thyroid cells (16).

This study therefore aimed to investigate the possible association between IGF-1 and the pathogenesis of thyroid nodules by determining serum IGF-1 levels in patients with thyroid nodules.

\section{Patients and methods}

Patients. A total of 56 patients with thyroid nodules were admitted to our hospital between March and July 2007 were randomly selected. The diagnosis of thyroid nodules in these patients was established by physical examination and ultrasound screening (ultrasound examinations were performed using Toshiba Nemio 17 equipment and a linear 7.5 MHz probe). After undergoing a radionuclide scan, the patients with thyroid nodules were divided into three groups: the 18 patients with hot thyroid nodules formed group 1; the 18 patients with solid cold thyroid nodules formed group 2; and the 20 patients with cystic cold thyroid nodules formed group 3. A control group of 18 healthy adults matched for age, gender and body mass index (group 0) was also included in the study (Table I). A physical examination, ultrasound and assays on the serum levels of thyroid-stimulating hormone (TSH), total triiodothyronine (TT3) and total thyroxine (TT4) were also performed on the individuals in the control group to exclude those with asymptomatic thyroid nodules. After an overnight fast of at least $8 \mathrm{~h}$, anthropometric measurements and blood samples were collected from each participant in the hospital by a team of trained research nurses and assistants. Blood samples were maintained in ice prior to transportation back to our laboratory for further processing. Complete blood images, renal and liver function tests, as well as lipid and glucose were assayed within $6 \mathrm{~h}$ of collection.

The exclusion criteria were: patients with diffuse goiter and iodine deficiency or hypothyroidism; patients who had been taking glucocorticoid medication within 1 week prior to the study (glucocorticoids are known to affect serum IGF-1 levels); patients who had been taking methotrexate; patients with hemolysis, jaundice or hyperlipidemia (all are known to affect serum IGF-1 levels); and diabetic patients with thyroid nodules (diabetic patients often have abnormal serum IGF-1 levels).

The study was approved by the Research Ethics Committee of the College of Medicine, Xi'an Jiaotong University. Informed consent was obtained from the patients and control subjects.

Ultrasound-guided fine-needle aspiration was performed on patients with cold thyroid nodules, using 21-gauge needles and 20-ml syringes. Patients were subject to follow-up following the aspiration. Subsequently, cystic fluid samples were prepared from patients with cystic cold thyroid nodules, and defined as group 4. Hyper-viscous cystic fluids in 3 patients were excluded (thus, cystic fluids from 17 patients were included in group 4).

Measurement of serum IGF-I levels. Fasting venous blood $(2 \mathrm{ml})$ was collected and maintained at room temperature for $5 \mathrm{~h}$. Subsequently, the blood samples were centrifuged for $5 \mathrm{~min}$ to harvest the supernatant, which was stored at $-20^{\circ} \mathrm{C}$ for later analysis. For each participant, the levels of the thyroid hormones, TT3, TT4 and TSH, were determined by radioimmunoassay. Free IGF-1 was determined using the Active non-extraction IGF-I immunoradiometric assay (IRMA) kit (DSL-2800, Inc., Webster, TX, USA), as previously described $(17,18)$. Briefly, this assay was a non-competitive assay in which the sample was sandwiched between two antibodies. It is a direct assay of the dissociable fraction of IGF-1. In the present study, the sensitivity was $0.03 \mathrm{ng} / \mathrm{ml}$ and inter- and intra- assay coefficients of variation were 9.9 and $10.1 \%$ (at 6.9 and $4.3 \mathrm{ng} / \mathrm{ml}$ ), respectively.

Statistical analysis. The measurement data were expressed as the mean \pm standard deviation (SD). The analysis of variance was performed by the t-test, and the correlation analysis by linear regression. Statistical analysis was performed using SPSS 11.5 software. $\mathrm{P}<0.05$ was considered to be statistically significant.

\section{Results}

The results of fine-needle aspiration biopsy in the 18 cases of solid cold thyroid nodules revealed that there were 10 patients with thyroid adenoma, 6 patients with thyroid goiter and 
Table II. IGF-1 levels in each group based on the result of fine-needle aspiration biopsy (mean $\pm \mathrm{SD}$ ).

\begin{tabular}{lrc}
\hline Group & No. & IGF-1 level (ng/ml) \\
\hline 0 & 18 & $200.33 \pm 126.51$ \\
P & 2 & $308.75 \pm 55.96$ \\
A & 13 & $264.03 \pm 118.97$ \\
G & 6 & $109.09 \pm 50.57$ \\
\hline
\end{tabular}

Group 0, control group; group P, patients with papillary carcinoma; group A, patients with thyroid adenoma; group $\mathrm{G}$, patients with thyroid goiter; IGF-1, insulin-like growth factor-1.

2 patients with papillary carcinoma. The serum IGF-1 levels progressively increased in the patients with thyroid goiter, thyroid adenoma and papillary carcinoma. Of the 20 patients with cystic cold thyroid nodules, there were 16 cases of a simple thyroid cyst, 3 cases of a thyroid cyst combined with thyroid adenoma and 1 case of a thyroid cyst combined with chronic lymphatic thyroiditis. The mean IGF-1 level in patients with thyroid cysts combined with thyroid adenoma was higher than that in cases with a thyroid cyst alone. The mean IGF-1 level in patients with thyroid adenoma was significantly higher than that in the control group $(\mathrm{P}<0.05)$ (Table II).

As shown in Table I, no significant difference in the age distribution was noted among the different groups $(\mathrm{P}<0.05)$. The IGF-1 levels revealed a gradual decreasing trend from group 2, through groups 0,3 and 1, to group 4 (Table III). The mean IGF-1 level in patients with solid cold thyroid nodules was significantly higher than that in patients with hot thyroid nodules $(\mathrm{P}<0.05)$, whereas the mean circulating IGF-1 level in patients with cystic cold thyroid nodules was significantly lower than that in the control group $(\mathrm{P}<0.05)$. The mean IGF-1 level in cystic fluids was significantly lower than that in the control group $(\mathrm{P}<0.05)$, and also lower than the mean circulating IGF-1 level in group $3(\mathrm{P}<0.05)$. In addition, the linear regression analysis suggested that IGF-1 had no significant correlation with the levels of TT3, TT4 and TSH.

\section{Discussion}

The incidence of thyroid nodules is approximately $4-7 \%$ in adults. Currently, ultrasound is the main technique available for thyroid nodule screening. A high-resolution ultrasound scan is capable of identifying thyroid nodules in approximately $40-50 \%$ of the general population (19), and with widespread use of the high-frequency ultrasound scan, the detection rate of thyroid nodules is increasing (20). Most sonographically-detected thyroid nodules are benign (21), and less than 7\% of nodules reveal malignancy (22). Furthermore, fine-needle aspiration cytology, providing a highly reliable means of differentiating between benign and malignant thyroid nodules, has been widely used in the clinical diagnosis of thyroid nodules due to its high accuracy and low cost (2). Thyroid radionuclide scanning is also a useful tool in the diagnosis and identification of thyroid nodules. Radioisotope imaging used to be the routine practice until the introduction
Table III. IGF-1 levels in each group (mean $\pm \mathrm{SD}$ ).

\begin{tabular}{lcc}
\hline Group & No. & IGF-1 level $(\mathrm{ng} / \mathrm{ml})$ \\
\hline 0 & 18 & $200.33 \pm 126.51$ \\
1 & 18 & $139.95 \pm 90.27$ \\
2 & 18 & $220.87 \pm 131.66$ \\
3 & 20 & $158.79 \pm 61.37$ \\
4 & 17 & $83.39 \pm 67.85$ \\
\hline
\end{tabular}

Group 0, control group; group 1, patients with hot thyroid nodules; group 2, patients with solid cold thyroid nodules; group 3, patients with cystic cold thyroid nodules; group 4, cystic fluid samples from patients with cystic cold thyroid nodules; IGF-1, insulin-like growth factor-1.

and widespread acceptance of fine-needle aspiration cytology (23). The majority of autonomous functioning thyroid adenomas are benign, and usually present as hot nodules on a radionuclide scan. Conversely, there is a chance of malignant lesions when radionuclide scanning reveals a cold nodule. However, finding a cold nodule on the radionuclide scan may also result from cystic thyroid conditions, bleeding or calcification. However, the mechanism for the development of the thyroid nodule has yet to be fully clarified.

IGF-1, a potent mitogen for numerous cell types, promotes the progression of mitosis via the promotion of DNA synthesis, and has long-term effects on cell proliferation, differentiation and apoptosis (6). It also plays a role in the transformation, infiltrative growth and metastasis of tumor cells (24). Shevah et al carried out a study on the relationship between malignant tumors and IGF-1 in 222 patients with congenital IGF-1 deficiencies (including Laron syndrome, GH gene deletion, GHRH receptor defects and IGF-1 resistance), and in 338 of their first-degree and second-degree relatives. The result revealed that none of the IGF-1-deficient patients developed cancer, whereas $9-24 \%$ of the family members had a history of malignancy, suggesting that congenital IGF-1 deficiency played a significant role in preventing the onset of the cancer (25). By contrast, Tita et al observed a relatively high incidence of thyroid cancer in acromegaly patients (26), indicating that high levels of serum IGF-1 play a part in the occurrence of thyroid neoplasm. Eszlinger et al observed lower concentrations of IGF-1 in cold nodules compared to surrounding normal tissues (27). These authors concluded that IGF-1 played a more prominent role during early clonal expansion and that aberrant intrinsic signaling through a somatic mutation conferred the predominant selective growth advantage in later stages of hot or cold nodules. High serum IGF-1 levels were correlated to thyroid nodules in males (28). In a further study (29), the expression level of IGF-1 in thyroid carcinoma tissues was found to be significantly higher than that of the control group. This increased expression level demonstrated that in the course of thyroid cancer progression, overexpressed IGF-1 stimulated the upregulation of IGF-1 receptors, leading to the association of excess IGF-1 with its receptor, which in turn resulted in an abnormal proliferation, differentiation and apoptosis of thyroid cells, and ultimately led to the development of thyroid cancer. 
In the current study, the concentration of serum IGF-1 in patients with hot nodules or cold nodules was not significantly different from that in the control group, which was consistent with the result of Hsiao et al (30). However, it was noted that no comparison based on further grouping of thyroid nodules was made in the study by Hsiao et al. In the further grouping analysis, the serum IGF-1 level in the hot nodule group was significantly lower than that in the solid cold nodule group and the control group, suggesting that circulating IGF-1 does not play any role in the pathogenesis of thyroid hot nodules. The IGF-1 level in cystic fluid from patients with cystic thyroid nodules was determined in the present study, and the results revealed that it was significantly lower than that in the control group, and also lower than the circulating IGF-1 level in these patients. Moreover, the circulating IGF-1 level in patients with cystic cold nodules was also significantly lower than that in the control group, suggesting that IGF-1 is not involved in the development of cystic thyroid nodules. However, no significant difference in IGF-1 levels was observed between the solid cold nodule group and the control group. In the further grouping analysis based on fine-needle aspiration cytology, the serum IGF-1 levels progressively increased in the patients with thyroid goiter, thyroid adenoma and papillary carcinoma. The mean IGF-1 levels in patients with thyroid adenoma were significantly higher than those in the control group. Thus, IGF-1 may play a significant role in the pathogenesis of certain solid cold thyroid nodules. Further studies are required to investigate the association between IGF-1 and solid cold thyroid nodules.

Few studies have addressed the fluctuation of IGF-1 levels in the various stages of human development thus far. Animal studies revealed that the circulating IGF-1 level was low in prenatal mice. After birth, IGF-1 produced by the liver becomes the major source of circulating IGF-1, and the level of circulating IGF-1 increases markedly in adolescence and adulthood (29). A previous study demonstrated that the IGF-1 level decreased with age in healthy males from early adulthood to old age (29). This indicated that tumor cell growth was probably growth factor-dependent in the early stages of cancer development, but became growth factor-independent in the later stages. In addition, IGF-1 and estrogen may play synergistic roles through the IGF-1 signaling cascade (31), which is consistent with the fact that thyroid nodules occur more frequently in females between 40 and 60 years old. Therefore, larger scale trials are required to further investigate the association between IGF-1 and thyroid nodules.

Although the exact site where IGF-1 exerts its effects remains unidentified, the experiments in vitro demonstrate that IGF-1 is capable of stimulating DNA synthesis, upregulating the expression of cyclin D1 and facilitating the transition from the G1 to the S phase. Furthermore, IGF-1 suppresses apoptosis and induces cell proliferation via modulation of the $\mathrm{Bcl}$ and $\mathrm{Bax}$ proteins (32). The protein-tyrosine kinase (PTK)-dependent signaling pathway, regulated by IGF-1, has also been proven to be capable of inducing thyroid proliferation (33). The binding of IGF-1 to the IGF-1 receptor initiates conformational changes in this tetrameric transmembrane receptor tyrosine kinase that initiates autophosphorylation and subsequent activation of Ras/Raf-mitogen-activated protein kinase (MAPK) and phosphatidylinositol 3-kinase (PI3K)/ protein kinase B (Akt) signaling cascades (34).
Serum IGF-1 is mainly produced by the liver and is regulated by age, gender, pubertal stage, nutritional status, the immune system, social factors, liver and renal functions, ethnicity, gene polymorphisms, GH and other hormones including thyroxine, cortisol, sex steroids and insulin $(35,36)$. Numerous factors are currently known to affect the level of circulating IGF-1, including age, diabetes (37), inflammatory bowel disease (38), hepatic disease (39), acromegaly (26), rheumatoid arthritis (40) and other carcinomas and conditions. Moreover, the administration of glucocorticoid agents also affect the circulating IGF-1 level (41). In this study, we have attempted to exclude any possible interfering factors, e.g., hemolysis, jaundice, hyperlipidemia, and the use of DNA synthesis-inhibiting drugs (e.g., methotrexate), by examining medical histories and conducting physical examinations.

Currently, there is a paucity of studies addressing the correlation of IGF-1 with thyroid nodules. Consequently, IGF-1 may exert its effect through autocrine and paracrine pathways; therefore, the use of circulating IGF-1 levels in predicting and diagnosing thyroid nodules is not advisable.

In conclusion, circulating IGF-1 may not be involved in the development of hot thyroid nodules and cystic cold nodules. It may play a significant role in the pathogenesis of certain solid cold thyroid nodules. Large scale trials and further studies are required to strengthen the relationship between IGF-1 and solid cold thyroid nodules, which may provide new insights into the pathogenesis of this condition, and reveal new means for the diagnosis and treatment of thyroid nodules in the future.

\section{Acknowledgements}

This study was supported by the National Nature Science Fund of China (no. 30500250) and Important Constructive Item of Xi'an Jiaotong University.

\section{References}

1. Carlson GW: Surgical anatomy of the neck. Surg Clin North Am 73: 837-852, 1993.

2. Alpay HC, Kalidag T, Keles E, Kaygusuz I, Yalcin S and Kapusuz Z: The effects of fine-needle biopsy on thyroid hormone levels. Otolaryngol Head Neck Surg 136: 942-945, 2007.

3. Welker MJ and Orlov D: Thyroid nodules. Am Fam Physician 67: 559-566, 2003.

4. Biersack HJ and Grunwald F: Thyroid cancer. N Engl J Med 345: 1216-1217, 2001.

5. LeRoith D and Roberts CT: Insulin-like growth factors. Ann N Y Acad Sci 692: 1-9, 1993.

6. Jones JI and Clemmons DR: Insulin-like growth factors and their binding proteins: biological actions. Endocr Rev 16: 3-34, 1995.

7. Jorgensen JO, Blum WF, Moller N, Ranke MB and Christiansen JS: Circadian patterns of serum insulin-like growth factor (IGF) II and IGF binding protein 3 in growth hormone-deficient patients and age- and sex-matched normal subjects. Acta Endocrinol (Copenh) 123: 257-262, 1990.

8. Laughlin GA, Barrett-Connor E, Criqui $\mathrm{MH}$ and Kritz-Silverstein D: The prospective association of serum insulin-like growth factor 1 (IGF-1) and IGF-binding protein-1 levels with all cause and cardiovascular disease mortality in older adults: the Rancho Bernardo study. J Clin Endocrinol Metab 89: 114-120, 2004.

9. Renehan AG, Zwahlen M, Minder C, O'Dwyer ST, Shalet SM and Egger M: Insulin-like growth factor (IGF-1), IGF binding protein-3, and cancer risk: systematic review and metaregression analysis. Lancet 363: 1346-1353, 2004.

10. Geusens PP and Boonen S: Osteoporosis and the growth hormone-insulin-like growth factor axis. Horm Res 58 (Suppl 3): 49-55, 2002. 
11. Pollak MN, Schernhammer ES and Hankinson SE: Insulin-like growth factors and neoplasia. Nat Rev Cancer 4: 505-518, 2004.

12. Wu X, Zhao $\mathrm{H}$, Ado $\mathrm{K}$, et al: Serum levels of insulin growth factor (IGF-1) and IGF-binding protein predict risk of second primary tumors in patients with head and neck cancer. Clin Cancer Res 10: 3988-3995, 2004.

13. Endogenous Hormones and Breast Cancer Collaborative Group Key TJ, Appleby PN, Reeves GK and Roddam AW: Insulin-like growth factor 1 (IGF1), IGF binding protein 3 (IGFBP3), and breast cancer risk: pooled individual data analysis of 17 prospective studies. Lancet Oncol 11: 530-542, 2010.

14. Mucci LA, Stark JR, Pollak MN, Li H, Kurth T, Stampfer MJ and Ma J: Plasma levels of acid-labile subunit, free insulin-like growth factor-I, and prostate cancer risk: a prospective study. Cancer Epidemiol Biomarkers Prev 19: 484-491, 2010.

15. Yu H, Spitz MR, Mistry J, Gu J, Hong WK and Wu X: Plasma levels of insulin-like growth factor-1 and lung cancer risk: a case-control analysis. J Natl Cancer Inst 91: 151-156, 1999.

16. Kimura T, van Keymeulen A, Golstein J, Fusco A, Dumont JE and Roger PP: Regulation of thyroid cell proliferation by TSH and other factors: a critical evaluation of in vitro models. Endocr Rev 22: 631-656, 2001.

17. Juul A, Holm K, Kastrup KW, et al: Free insulin-like growth factor I serum levels in 1430 healthy children and adults, and its diagnostic value in patients suspected of growth hormone deficiency. J Clin Endocrinol Metab 82: 2497-2502, 1997.

18. Zimmermann-Belsing T, Juul A, Juul Holst J and Feldt-Rasmussen U: The insulin-like growth axis in patients with autoimmune thyrotoxicosis: effect of antithyroid drug treatment. Growth Horm IGF Res 14: 235-244, 2004.

19. Desser TS and Kamaya A: Ultrasound of thyroid nodules. Neuroimaging Clin N Am 18: 463-478, 2008.

20. Frates MC, Benson CB, Charboneau JW, Cibas ES, Clark OH, Coleman BG, Cronan JJ, Doubilet PM, Evans DB, Goellner JR, Hay ID, Hertzberg BS, Intenzo CM, Jeffrey RB, Langer JE, Larsen PR, Mandel SJ, Middleton WD, Reading CC, Sherman SI, Tessler FN and Society of Radiologists in Ultrasound: Management of thyroid nodules detected at US: Society of Radiologists in Ultrasound consensus conference statement. Radiology 237: 794-800, 2005.

21. Cappelli C, Pirola I, Cumetti D, et al: Is the anteroposterior and transverse diameter ratio of nonpalpable thyroid nodules a sonographic criteria for recommending fine-needle aspiration cytology? Clin Endocrinol (Oxf) 63: 689-693, 2005.

22. Papini E, Guglielmi R, Bianchini A, et al: Risk of malignancy in nonpalpable thyroid nodules: predictive value of ultrasound and color-Doppler features. J Clin Endocrinol Metab 87: 1941-1946, 2002

23. Sriram U and Patacsil LM: Thyroid nodules. Dis Mon 50: 486-526, 2004

24. LeRoith D and Roberts CT: The insulin-like growth factor system and cancer. Cancer Lett 95: 127-137, 2003.

25. Shevah $\mathrm{O}$ and Laron Z: Patients with congenital deficiency of IGF-1 seem protected from the development of malignancies: a preliminary report. Growth Horm IGF Res 17: 54-57, 2007.
26. Tita P, Ambrosio MR, Scollo C, et al: High prevalence of differentiated thyroid carcinoma in acromegaly. Clin Endocrinol (Oxf) 63: 161-167, 2005

27. Eszlinger M, Krohn K, Kratzsch J, Voigt C and Paschke R: Growth factor expression in cold and hot thyroid nodules. Thyroid 11: 125-135, 2001.

28. Völzke H, Friedrich N, Schipf S, et al: Association between serum insulin-like growth factor-1 levels and thyroid disorders in a population-based study. J Clin Endocrinol Metab 92: 4039-4045, 2007.

29. Leifke E, Gorenoi V, Wichers C, von Zur Mühlen A, von Büren E and Brabant G.: Age-related changes of serum sex hormones, insulin-like growth factor-1 and sex-hormone binding globulin levels in men: cross-sectional data from a healthy male cohort. Clin Endocrinol (Oxf) 53: 689-695, 2000

30. Hsiao PJ and Tsai JH: Increased insulin-like growth factor-1 receptors in thyroid tissues of Graves' disease. J Formos Med Assoc 93: 925-32, 1994.

31. Surmacz E and Bartucci M: Role of estrogen receptor alpha in modulating IGF-I receptor signaling and function in breast cancer. J Exp Clin Cancer Res 23: 385-394, 2004.

32. Ingbar $\mathrm{SH}$, Tramontano $\mathrm{D}$ and Amebesi-Impiombato $\mathrm{S}$ : Observations on the regulation of thyroid cell growth. Horm Metab Res Suppl 17: 43-51, 1987.

33. Ciampolillo A, de Tullio $\mathrm{C}$ and Giorgino F: The IGF-1/IGF-1 receptor pathway: implications in the pathophysiology of thyroid cancer. Curr Med Chem 12: 2881-2891, 2005.

34. Barnes CJ, Ohshiro K, Rayala SK, El-Naggar AK and Kumar R: Insulin-like growth factor receptor as a therapeutic target in head and neck cancer. Clin Cancer Res 13: 4291-4299, 2007.

35. Clemmons DR: Clinical utility of measurements of insulin-like growth factor 1. Nat Clin Pract Endocrinol Metab 2: 436-446, 2006

36. Clayton PE and Hall CM: Insulin-like growth factor I levels in healthy children. Horm Res 62 (Suppl 1): 2-7, 2004.

37. Maes M, Underwood LE and Ketelslegers JM: Low serum somatomedin- $C$ in insulin-dependent diabetes: evidence for a postreceptor mechanism. Endocrinology 118: 377-382, 1986.

38. Kirschner BS and Sutton MM: Somatomedin-C levels in growth-impaired children and adolescents with chronic inflammatory bowel disease. Gastroenterology 91: 830-836, 1986.

39. Wu JC, Daughaday WH, Lee SD, et al: Radioimmunoassay of serum IGF-I and IGF-II in patients with chronic liver diseases and hepatocellular carcinoma with or without hypoglycemia. J Lab Clin Med 112: 589-594, 1988.

40. Foppiani L, Sulli A, Prete C, et al: Desmopressin, ovine CRH, and low-dose ACTH tests: tools for the study of the hypothalamic-pituitary-adrenal axis in premenopausal rheumatoid arthritis patients. Ann N Y Acad Sci 876: 83-87, 1999.

41. Hochberg Z: Mechanisms of steroid impairment of growth Horm Res 58 (Suppl 1): 33-38, 2002. 